\title{
Bullying e cyberbullying: hoja de ruta y principales retos para la intervención ${ }^{1}$
}

\section{Bullying e cyberbullying: procedimento e principais desafios para intervenção}

\section{Bullying and cyberbullying: main challenges and procedure for an intervention}

Ana Maria Pérez Vallejo*

\section{Resumen}

Este estudio quiere realizar un diagnóstico sobre la situación actual de la violencia entre iguales y sus nuevas formas de manifestarse. El estado de la cuestión a nivel mundial podría calificarse de alarmante, más aún por el impacto de las TICs. El ciberespacio es cada vez más utilizado por menores poco vigilados por sus padres y se advierte sobre el creciente uso de las redes sociales para ejercer violencia, intimidación ensañamiento o humillación pública entre iguales. El anonimato y difusión que proporcionan las redes sociales hacen más intenso el fenómeno del bullying tradicional, generando un proceso concurrente de ciberbullying. Sobre esta realidad nos proponemos evaluar las carencias y necesidades detectadas a distintos niveles, revisar los recursos existentes en la actualidad y plantear propuestas de intervención socio-legal. Por lo que el abordaje de esta problemática y su actual estado de la cuestión será analizado desde un análisis trasversal.

Palabras clave: Violencia entre iguales. Acoso escolar. Ciberacoso. Diagnostico. Prospectiva.

Este trabajo se realiza en ejecución del Proyecto I+D+I del Programa Estatal de Investigación, Desarrollo e Innovación Orientada a los Retos de la Sociedad: "Análisis jurídico y cuantitativo de la violencia en la infancia y adolescencia: propuestas de intervención socio-legal" (DER201458084-R). Investigador Principal: Pérez Vallejo, A. Ma y García García J.

Doctora em Derecho. Profesora Titular de Derecho civil na Universidad de Almería. Almería España. E-mail: amperez@ual.es. 


\section{Resumo}

Este estudo pretende realizar um diagnóstico sobre a atual situação de violência entre iguais e suas novas formas de se manifestar. O estado da questão em nível mundial poderia qualificar-se como alarmante, ainda mais pelo impacto das TICs. O cyberespaço é cada vez mais utilizado por menores pouco monitorados por seus pais e adverte-se sobre o crescente uso das redes sociais para exercer violência, intimidação, crueldade ou humilhação pública entre iguais. $O$ anonimato e a difusão que as redes sociais proporcionam fazem mais intenso o fenômeno do bullying tradicional, gerando um processo simultâneo de cyberbullying. Sobre esta realidade, nos propomos a avaliar as carências e as necessidades detectadas em niveis distintos, revisar os recursos existentes na atualidade e propor propostas de intervenção sociolegais. Portanto, a abordagem desta problemática e o atual estado da questão serão analisados a partir de uma análise transversal.

Palavras-chave: Violência entre iguais. Bullying. Cyberbullying. Diagnóstico. Perspectivas.

\section{Abstract}

This study wants to make a diagnosis about the current situation of violence between equals and their new forms of manifestation. The state of the issue at the global level could be termed alarming, more so because of the impact of ICTs. Cyberspace is increasingly being used by children who are undermonitored by their parents and warns of the growing use of social networks to exert violence, intimidation, or public humiliation among peers. The anonymity and diffusion provided by social networks make the phenomenon of traditional bullying more intense, generating a concurrent cyberbullying process. On this reality we propose to evaluate the deficiencies and needs detected at different levels, to review the existing resources and to propose proposals for socio-legal intervention. So the approach of this problem and its current state of the issue will be analyzed from a cross-sectional analysis.

Keywords: Violence between peers. Bullying. Cyberbullying. Diagnosis. Prospective. 


\section{Introducción}

Las cifras del bullying, ciberbullying y otros tipos de acoso en la red son alarmantes y no presentan realidades muy distintas a nivel mundial. Su manifestación implica exclusión social, intimidación y maltrato infantil. Conductas reprochables que generan drásticas consecuencias, principalmente a la víctima, pero también a todos los implicados, directa o indirectamente. Los afectados no sólo son los niños, niñas y adolescentes agredidos, sino también los agresores y testigos (espectadores u observadores) que conforman todos ellos lo que se denomina el "triángulo de bullying"

Ante este fenómeno concurren un cúmulo de silencios en cadena o comportamientos omisivos que han contribuido sobremanera al desconocimiento de la magnitud o alcance de la problemática que abordamos; y lo que es peor, la denominada "conspiración del silencio" agrava significativamente la situación de debilidad y de vulnerabilidad de las víctimas. En este contexto, se hace necesario contribuir a transformar modelos de comportamientos antisociales y garantizar una infancia protegida de la violencia por ser un factor crucial en el proceso de desarrollo de la humanidad. Proponer estrategias concretas de prevención, detección, atención y apoyo jurídico eficiente a víctimas y victimarios es nuestro objetivo.

\section{Violencia entre iguales: estado de la cuestión}

\subsection{Bullying tradicional y nuevas modalidades de ciberacoso en el entorno escolar}

Se afirma que la violencia en el entorno escolar se presenta como una manifestación más del malestar que está inundando todo el sistema educativo, pero cuyas raíces debemos situarlas en el contexto más amplio de una sociedad cada vez más dura e individualista, más competitiva y violenta. A los problemas de disciplina y disrupción en el aula, agresiones indirectas 0 actos de vandalismo, se unen episodios violencia de los alumnos hacia el personal docente (jerarquía de 
la relación), y de alumnos hacia alumnos (simetría horizontal en la relación). Esta forma de violencia entre iguales puede manifestarse de forma directa (agresiones físicas o peleas) y maltrato psíquico o emocional (bullying y ciberbullying). Pero no todo acto de violencia es acoso; precisamente, será la nota de la repetición y diferencia de poder que se establece entre la persona acosada y la acosadora, la que sitúa la barrera entre lo que se puede admitir como un comportamiento corriente inherente a la propia convivencia y los conflictos, frente a una situación de acoso (GAIRÍN, 2013, p. 27). La realidad refleja con datos significativos como aumentan los casos de menores que son objeto de persecución psíquica y física, presencialmente y además, en las redes sociales. Por lo que esta situación de intimidación y hostigamiento prolongados en el tiempo puede durar las 24 horas del día. Cabe reseñar que recientes estudios afirman la co-ocurrencia entre los fenómenos del bullying tradicional y el más moderno ciberbullying. (DEL REY, 2012, p. 608). Al respecto conviene aclarar que en el ciberacoso deben concurrir los tres elementos básicos del acoso escolar: intencionalidad ${ }^{1}$ repetición, y desequilibrio de poder; añadiendo la peculiaridad de que se produce a través de las TICs, como medio para recibir y ejercer el maltrato. Pero como señala Save the Children (ORJUELA LÓPEZ et al., 2013, p. 22) estas características tienen matices propios. $Y$ es que la repetición ya no consistiría en agredir a un niño o niña varias veces, sino que bastaría con subir una sola vez una imagen indeseada a una red social y que la vean varias personas. La repetición se produciría cada vez que se vea esa imagen, se comparta o los comentarios abusivos que la pueden acompañar.

En esta línea, y desde distintos sectores, surgen alertas ante las nuevas pautas de comportamiento entre menores que se conocen dentro del mismo círculo educativo. Así ocurre con la distribución de

\footnotetext{
Cabe reseñar, en lo que se refiere a la intencionalidad, la falta de unanimidad de criterios. La Sentencia de la Audiencia Provincial de Madrid de 16 de septiembre de 2014 (AC 2015/1056) señala que "el bullying, a diferencia de otros tipos de acoso adulto, no siempre tiene una finalidad intencionada consciente".
} 
imágenes de agresiones físicas a otros niños tomadas con la cámara de un móvil «happy slapping»; o el uso de la aplicación Snapchat ${ }^{2}$ para subir cualquier tipo de imagen, que se borra en pocos segundos sin dejar rastro ni registro. A la vez, resulta preocupante el uso de las TICS para la comisión de nuevas conductas de ciberacoso sexual (child grooming) ${ }^{3}$ donde el agresor puede ser un mayor o menor de edad y la víctima es siempre un menor. O las mas expandidas conductas de sexting o difusión de imágenes comprometidas de contenido sexual, que en ocasiones pueden ser el paso previo a la "sextorsión". Con la peculiaridad de que la filtración de ese contenido sensible puede aparecer vinculado al entorno escolar para humillar o ridicularizar al afectado, generando un proceso concurrente de ciberbullying; y lo que es peor, se afirma que estas conductas se dan cada vez a edades más tempranas. Nótese que el uso de las TICs por la población infantil (de 10 a 15 años) es muy elevada. Así, el uso del ordenador es prácticamente universal $(95,2 \%)$ y el $91,8 \%$ utiliza Internet. Y el uso del móvil es cada vez más precoz entre la población infantil. El 50,9\% de los niños españoles de 11 años ya dispone un móvil, una proporción que crece hasta el 93,9\% entre los de 15 años ${ }^{4}$. Datos que no serían preocupantes si se hiciera un uso responsable de estos dispositivos y hubiese un adecuado control parental. Por no ser las cosas así, es un dato incuestionable que el ciberespacio es cada vez más utilizado por menores poco vigilados por sus padres y desde distintos sectores se advierte sobre el creciente uso de las redes sociales para ejercer violencia, intimidación ensañamiento o humillación pública entre iguales.

2 Disponible en: <https://www.fiscal.es/memorias/memoria2016/FISCALIA_SITE/index.html.>.

3 La conducta de "child grooming" consiste en realizar acciones deliberadamente con el fin de establecer una relación y un control emocional sobre un menor con el fin de preparar el terreno para el posterior abuso sexual. El contacto tiene que ser por medio tecnológico (Internet, teléfono o cualquiera otra tecnología de información y la comunicación). La STS de 24 de Febrero 2015 (RJ 2015/1405) señala al respecto que se trata de un listado abierto. En el caso de autos el contacto se produjo por medio de la red social Facebook, que se ubica en Internet, la menor contactada tenía 12 años.

$4 \quad$ Véase la Encuesta sobre Equipamiento y Uso de Tecnologías de Información y Comunicación en los Hogares correspondiente a 2016 que elabora el Instituto Nacional de Estadística. (Publicado el 3 de octubre de 2016). Disponible en: <http://www.ine.es>. 


\subsection{Las cifras del bullying y ciberbullying. El perfil de la víctima $y$ agresor}

A nivel mundial, se reitera que las cifras del acoso se han disparado. Algunas noticias son reveladoras de la gravedad y magnitud del problema que sometemos a consideración. En el Día Internacional de la Juventud, una nueva encuesta señala que dos tercios de los jóvenes en más de 18 países dicen haber sido víctimas de acoso escolar (UNICEF, 2016). ${ }^{5}$ De forma paralela y bajo el alarmante titular "Veinticuatro millones de niños y jóvenes europeos sufren acoso" ya sea presencial o a través de las nuevas tecnologías, se dan a conocer estas cifras cuando miembros de la fundación británica Beat Bullying han defendido en la sede del Parlamento Europeo la necesidad de prestar más atención al problema del acoso. Según la organización, siete de cada diez jóvenes han experimentado alguna forma de acoso o intimidación, ya sea en forma verbal, psicológica o física, algo que puede tener consecuencias para el resto de sus vidas. Esta noticia también revela que «en la Unión Europea, 1.712 niños y jóvenes se han quitado la vida para librarse del tormento del acoso». En este contexto, el Annual Bullying Survey (2016), en una encuesta realizada a 8.850 jóvenes de edades comprendidas entre los 12 a 20 años de edad de Reino Unido, deja entrever que las secuelas del acoso se prolongarán irremediablemente en el tiempo. Los resultados indican que el $44 \%$ de los jóvenes que han sido acosados o intimidados experimentan depresión. El $41 \%$ ansiedad social y el $33 \%$ de los que están siendo intimidados tienen pensamientos suicidas. A fecha de hoy podemos afirmar que bullying y el ciberbullying es un factor de riesgo de suicidio en la infancia y adolescencia.

En España, siguiendo la misma línea, estudios recientes, revelan cómo los actos de violencia entre iguales, en particular en el entorno escolar, alcanzan un nivel preocupante. Entre ellos cabe destacar la investigación realizada en base a los datos de 32 estudios incluidos en

Nota de prensa UNICEF (12.8.2016). Disponible en: <https://old.unicef.es/sala-prensa/dostercios-de-los-jovenes-en-mas-de-18-paises-dicen-haber-sido-victimas-de-acoso>. 
la revisión sistemática y que incluye a unos 120.000 menores de edad. Los resultados obtenidos por el equipo investigador, indican una tasa de prevalencia global del $11,45 \%$ para el acoso escolar. Si se analiza por tipo de intimidación, se encontró una tasa más alta de acoso tradicional, en el $13,30 \%$, lo que incluye el acoso físico, verbal y relacional o social, en contraste con el ciberacoso, que llegó a 7,62\%; los menores de edad que habían sido víctimas de ambos tipos de intimidación representa un porcentaje menor, en el 6,9\% (GARCÍA GARCÍA et al, 2017, p. 129) Datos que vienen a ser muy similares a otros de este mismo año, como los detallados en el informe "Yo a eso no juego. Bullying y ciberbullying en la infancia" que apunta cómo un 9,3\% ha sufrido acoso y un 6,9\% ciberacoso. (Save the Children, 2016, p. 29) ${ }^{7}$. Y también a los obtenidos en el primer estudio que analiza el fenómeno del ciberbullying desde la perspectiva de los menores afectados, que situa en el 6,9\% a las víctimas de ciberbullying. (Fundación ANAR y Mutua Madrileña 2016, p. 26-27) ${ }^{8}$. Este trabajo aporta un dato muy significativo; y es que, el teléfono móvil es la herramienta más habitual para acosar telemáticamente y el WhatsApp es la aplicación más utilizada (por esta vía sufre el $81 \%$ de los afectados, mientras que por las redes sociales se da el $36,2 \%$ del ciberacoso). Supone ya uno de cada cuatro casos de acoso escolar.

En otro orden de cosas pero vinculadas a lo anteriormente expuesto, nos cuestionamos si a fecha de hoy existen unos rasgos o indicadores prevalentes para ser víctima o agresor. En lo que a la víctima se refiere, no existe un perfil específico, si bien, algunas investigaciones apuntan que este riesgo es mayor cuando existe sobreprotección por parte de los padres; o bien, que los niños que pertenecen a familias

$6 \quad$ El estudio se realiza en ejecución del Proyecto I+D+| "Análisis jurídico y cuantitativo de la violencia en la infancia y adolescencia: propuestas de intervención socio-legal” (DER2014-58084-R).

7 Para la elaboración del informe se han entrevistado a 21.487 estudiantes, de entre 12 y 16 años de edad. Al ser una encuesta representativa, detalla el trabajo, los resultados se pueden extrapolar al conjunto de la población, con el resultado de que el numero de estudiantes de centros públicos que han sufrido acoso tradicional es de 111.000 y 82.000 ciberacoso.

8 El informe se realiza con una muestra de niños/as y adolescentes que han sufrido acoso escolar y que han llamado al Teléfono ANAR entre los años 2013 y 2015 . El informe revela que los casos de acoso escolar atendidos en 2015 crecieron un $75 \%$ frente al año anterior. 
socialmente aisladas o que viven en un ambiente familiar conflictivo, son más propensos a padecerlo (MARTíNEZ AMORÓS, 2010, p. 119). Así puede deducirse, que la victimización previa del menor es un factor de riesgo tanto en bullying tradicional como en cyberbullying, aunque no siempre. Así lo refieren algunos estudios (DEL REY, 2012, p. 608-613; ANAR, 2016, p. 46) y lo confirman algunos pronunciamientos judiciales (Sentencia de la Audiencia Provincial de la Rioja de 8 de enero de $2015)^{9}$. Pero lo que no admite matices es que las víctimas habituales de ensañamiento son muchachos y muchachas pacíficos, tímidos, introvertidos y, sobre todo, vulnerables (ROJAS MARCOS, 2005). Con frecuencia, muestran aspectos físicos, orientación sexual, actitudes o hábitos diferentes a los de la mayoría de la clase, que en ocasiones se hacen visibles a golpe de trágicos titulares en medios de comunicación ${ }^{10}$. Queremos significar intencionadamente y a los efectos de una eventual responsabilidad, que el hecho de que el menor víctima de acoso sea un tanto tímida, cohibida, discreta o retraída o con más o menos dificultades de integración social y escolar, no solo no limita la responsabilidad del Colegio, sino que la agrava. Así lo señala la Sentencia de la Audiencia Provincial de Palencia de 18 marzo de $2016^{11}$, que califica de "reprochable" en el ámbito de la culpa civil la reacción del Colegio. "Precisamente su carácter y vulnerabilidad exigen un especial deber de vigilancia sobre su entorno académico y sobre su relación con sus compañeras de clase por parte de profesores y tutores".

$9 \quad$ En el caso de autos consta probado que el menor acosado fue objeto de hostigamiento y que padece un cuadro de trastorno ansioso-depresivo. Los informes médicos y psicológicos expresan como factor concurrente "la posible influencia en ese estado de la conflictividad parental que el menor vive en su casa" Vid. SAP de la Rioja (Sección $1^{a}$ ) n $n^{\circ} 2 / 2015$ de 8 enero (ARP/2015/112).

10 Carla, con tan solo 14 de edad, se lanzó desde un acantilado en abril de 2013. Sufría acoso permanente. "La llamaban bizca, bollera. Le hacían rimas: 'Topacio, un ojo para aquí y otro para el espacio'. Otra menor, Arancha, de 16 años, estudiante con discapacidad intelectual y motora, era acosada por un menor de 17 años por el móvil. Le decía "Guarra, ¿qué dices de mí? Voy a ir a pegarte con mis primas. Me cago en tus muertos. Me vas a dar 50 euros o voy a ir con mis primas y más gente a pegarte". La menor no aguantó más y se despidió de sus amigas por WhatsApp diciendo: "Estoy cansada de vivir" (2015). Alan, se suicidó en Barcelona en la Nochebuena de 2015, 20 días después de haberse convertido en el primer menor transexual de Cataluña, en obtener un cambio del DNI acorde con su sexo sentido.,

11 Vid. SAP de Palencia (Sección 1a). Sentencia n. 55/2016, de 18 marzo. (AC 2016/425). 
Por otra parte, en relación a los agresores, se afirma, que la conducta de acoso u hostigamiento puede surgir de la propia vinculación conflictiva con el niño acosado; "algo del niño les molesta, le ven vulnerable, se sienten incómodos o les cae mal"12. Pero hay consenso en que los maltratadores suelen ser personajes inseguros y provocadores, que no han madurado la capacidad de sentir compasión ante el sufrimiento ajeno (ROJAS MARCOS, 2005); y que tras ellos normalmente hay familias «inconsistentes». Padres y madres que no han puesto límites, que no han enseñado a sus hijos a respetar las normas y que tienen un escaso control y supervisión sobre la vida de sus hijos (GAIRÍN SALLÁN, 2013, p. 25). También en este punto cabe significar la responsabilidad en la que incurren los progenitores de los agresores, cuando advertidos por el propio Centro, no adoptan medidas disciplinarias, educativas o terapéuticas para poner freno al problema, dificultando el desarrollo de medidas en tiempo real y útil y agravando drásticamente la situación, tanto para la víctima como para el propio agresor. De no recibir un tratamiento firme que les conduzca a percibir los efectos negativos de su comportamiento, - que en ningún caso ha de resultar impune -, se verá reforzada su conducta antisocial con grandes probabilidades de que persista en su vida adulta. El citado Informe Cisneros $X$ apunta que el $60 \%$ de los niños que participan en conductas de acoso cometerán un delito antes de los 24 años de edad.

\section{La importancia de la edad.}

\subsection{Prevalencia de las conductas de acoso y ciberacoso por tramos de edad y sexo}

Hace más de una década, los datos extraídos del Informe Cisneros X sobre "Acoso y Violencia Escolar" (OÑATE y PIÑUEL, 2006), apuntaban como edades más conflictivas, la de los 11 a 14 años. Datos que se confirman con un sesgo a la baja en el reciente Informe ANAR que sitúan la edad media en los 11-13 años (caen a partir de esta edad).

12 Vid. SAP de Madrid (Sección 8 ${ }^{\text {a }}$ ) Sentencia n. 373/2014, de 16 de septiembre. (AC 2015/1056). 
Por tipo de acoso, las víctimas de ciberbullying tienen una edad media de 13,6 años, y otros tipos de acoso escolar, desciende hasta 11,6 años. Y por sexo, en el ciberbullying se observa una presencia de mujeres muy superior a la de varones (70,2\% frente a $29,8 \%)$; por cada varón que sufre ciberbullying, existen 2,4 mujeres en estas mismas circunstancias. Este Informe revela además otros datos significativos relativos a los adolescentes de entre 13 y 17 años. En este tramo de edad son los que más sufren ciberbullying (el $36,5 \%$ ), en forma de insultos y ofensas de palabra el $84,5 \%$ y amenzas el $24,3 \%$ (ANAR, 2016, p. 32 y 40 ). En la misma línea, el Informe Save the Children señala que las chicas salen peor paradas, tanto en el caso de caso tradicional como en el ciberbullying: un 10,6\% han sufrido acoso (frente a un $8 \%$ de chicos), y un $8,5 \%$ ciberacoso (frente a un $5,3 \%$ de chicos) (Save the Children, 2016) $)^{13}$.

Datos que en líneas generales vienen a coincidir con los reseñados en la Memoria de la Fiscalía General del Estado, pero claro está, referidos a casos ya judicializados y en sede de jurisdicción de menores. Tanto en la Memoria de 2015 como en la de $2016^{14}$ apuntan que gran parte de los casos de acoso escolar son protagonizados por menores que no han alcanzado los catorce años. $Y$ en cuanto a los delitos cometidos o difundidos por vía informática, aunque tampoco hay estadísticas, sigue percibiéndose un uso inadecuado de móviles smartphone, cada vez más incluso entre menores que no llegan a catorce años; igualmente se señala que se han incrementado las conductas de sexting entre menores de esas edades. No obstante, en las distintas sentencias consultadas comprobamos como en muchos casos de bullying y ciberbulliyng concurren menores de 14 años (inimputables) con otros menores

13 Para la elaboración del informe se han entrevistado a 21.487 estudiantes, de entre 12 y 16 años de edad. Vid. Informe "Yo a eso no juego. Bullying y ciberbullying en la infancia". Save the Children, España). La encuesta se realiza de los estudiantes de ESO (de 12 a 16 años) AA.VV. (Coord. Ana Sastre) Febrero 2016, p. 29.

14 Vid. Memoria de la Fiscalía General del Estado (2015) en el Apartado 6.- Menores 6.2.2.1. Referencia a delitos en particular, apartado g) Violencia en el ámbito escolar. En igual sentido la Memoria de 2016. Véase el Apartado 6.2.2.9 Delitos cometidos o difundidos por vía informática. Disponible en: < https://www.fiscal.es/memorias/memoria2016/FISCALIA_SITE/index.html>. 
situados en el tramo de los 14 a 17 años (imputables). La Memoria de 2016 señala el aumento de denuncias por hechos delictivos cometidos a través de mensajería instantánea (WhatsApp); y hace una llamada de atención sobre el uso cada vez más generalizado de aplicaciones como las snapchat, que dificultan más la obtención de medios de prueba y el control parental, siendo llamativo que dicha aplicación sea accesible para mayores de once años. En lo que se refiere a las conductas de acoso con elementos sexuales (child grooming y sexting) no existen cifras. Pero -a modo de alerta- un estudio realizado a una muestra de menores de entre 11 y 16 años en el marco del Proyecto europeo EU Kids online ${ }^{15}$, arroja entre otros, datos preocupantes cómo que el $21 \%$ de los niños entrevistados han tenido contacto online con alguien que no han conocido cara a cara, y el $9 \%$ han acordado un encuentro con alguien que han conocido solo a través de Internet, siendo los menores de entre 13 y 16 años los más proclives a estas conductas. En el caso de conductas conocidas como sexting, se advierte desde distintos sectores, que el envío de fotos comprometidas, es una de las acciones más comunes en adolescentes incluidos también en este tramo de edad. Según los datos publicados en la guía sobre sexting del Instituto Nacional de Tecnologías de la Comunicación (Inteco) y Pantallas Amigas, el 8,1\% de los adolescentes españoles de 10 a 16 años reconoce haber recibido en su teléfono móvil fotos o vídeos de chicos o chicas conocidos en una postura sexy. El 4\% reconoce haber protagonizado este tipo de imágenes ${ }^{16}$.

\subsection{Conductas antijurídicas. Respuesta del sistema judicial a la violencia entre iguales}

La progresiva judicialización de los casos de bullying, ciberbullying, grooming y sexting es una realidad. Estas conductas

\footnotetext{
15 Este estudio realizado en la Universidad del País Vasco puede consultarse en: < http://www. prentsa.ehu.es/p251 content/es/contenidos/noticia/20110328_internet_kids/es_interkid/adjuntos /Informe_Espa\%C3\%B1a_completo_red.pdf>.

16 Vid. Instituto Nacional de Ciberseguridad de España (INTECO). Disponible en: < https://www. incibe.es/guias/Guia_sexting>.
} 
antijurídicas, además del reproche criminal que merecen, conforme a la legislación penal del menor producen un daño efectivo, que nadie tiene obligación de soportar; por lo que ese daño, injustamente causado, da lugar al nacimiento de la correspondiente responsabilidad civil, donde estarán implicados uno o varios menores (agresores y víctimas), sus progenitores o representantes legales y guardadores (Centro docente). Debe repararse que en estos casos ya hay denuncia del propio Colegio, y evidentemente de los padres del menor. Por lo que víctimas y autores de estas conductas se incorporan al proceso, con el consiguiente efecto estigmatizante que procura el aparato judicial.

En líneas anteriores hemos apuntado deliberadamente la prevalencia de las conductas antijurídicas por tramos de edad, para esbozar a continuación el régimen regulador de la responsabilidad penal y civil que deriva de las mismas ${ }^{17}$. Como se ha visto, hay prevalencia en la comisión de conductas de acoso por parte de menores que no alcanzan los 14 años (inimputables). Pero los daños derivados de sus conductas antijurídicas no quedan impunes y deben resarcirse siguiendo las reglas generales de la responsabilidad civil extracontractual (ex artículos 1902 y 1903 Código civil). Acción de responsabilidad civil que se entablará bien, ante la jurisdicción civil, cuando se demande a los padres del acosador (culpa in educando) o al Centro docente privado (culpa in vigilando) o a ambos a la vez; o bien, ante la jurisdicción contenciosa cuando el menor está bajo la guarda de la Administración Pública (Centro docente público) $)^{18}$.

También se ha visto la prevalencia de conductas de ciberacoso entre los menores de entre 13 y 16 años. Este tramo de edad es trascendente, pues los menores de entre 14 y 18 años son responsables

17 Vid. PÉREZ VALLEJO, A.M. "El complejo régimen que disciplina la responsabilidad civil por daños derivados del acoso escolar". Anuario de Derecho Civil. Tomo LXVIII fasc. IV (2015), p. 1387-1452. Disponible en: <http://hdl.handle.net/10835/4447>.

18 Aplicándose también en esta sede jurisdiccional las reglas generales civiles, junto a las establecidas hasta ahora en los arts. 139 y siguientes de la Ley 30/1992, de 26 de noviembre (LRJAP), regulándose desde el 2 de octubre de 2016 por los arts. 32 y ss. de la Ley 40/2015, de 1 de octubre, de Régimen Jurídico del Sector Público. 
penal y civilmente también. Por lo se le aplicarán los tipos penales previstos en el Código Penal de los adultos y la Ley Orgánica 5/2000, de 12 de enero, reguladora de la Responsabilidad Civil y Penal del Menor (en adelante LORPM). Un breve apunte nos lleva a señalar que el 1 de julio de 2015 entró en vigor la LO 1/2015, de 30 de marzo, por la que se modifica la LO 10/1995, de 23 de noviembre, del Código Penal, que suprime el Título III bajo la rúbrica "De las faltas". Sin embargo, ello no comporta la despenalización de todas las conductas anteriormente calificadas como faltas y en las que se subsumen algunas conductas de acoso escolar; sino que se mantienen, reubicando su contenido y calificándose como "delito leve". Para clarificar la cuestión debemos referir que antes de la reforma de 2015, las conductas de acoso se subsumían en el delito o falta de lesiones físicas y psíquicas del artículo $147 \mathrm{CP}$; hoy se mantienen como delito de lesiones (artículo 147.1 CP) y como "delito leve", las lesiones de menor entidad, en el artículo 147.2 CP. También en la falta de maltrato de obra del viejo artículo 617 CP, hoy calificadas como delito leve de maltrato de obra en el artículo 147.3 CP. Igualmente el acosador o acosadores podían incurrir en una falta de vejación injusta del artículo $6202^{\circ} \mathrm{CP}$, hoy calificadas como delito de vejaciones injustas de carácter leve en el artículo 173.4 CP; e incluso, en un delito de amenazas del art.169 y en un delito leve de amenazas y coacciones del vigente artículo 171.7 y 172.3 CP, respectivamente. Tipos penales que en ocasiones, pueden entrar en concurso con el delito contra la integridad moral, previsto y penado en el artículo $173.1 \mathrm{CP}$ que es el de mayor aplicación en los supuestos de bullying y ciberbullying. Paralelamente con la nueva reforma se regula ex novo del delito de acoso permanente (art. 172 ter $\mathrm{CP}$ ), que será de especial significación en los casos de acoso escolar.

En cuanto a las otras modalidad de acoso con elementos sexuales, el delito de child grooming se tipifica tras la reforma de 2015 en el artículo 183 ter 1 CP. La edad del sujeto pasivo (víctima) se sitúa ahora en los menores de 16 años y la edad del agresor, al no excluirlo 
el tipo ${ }^{19}$, podría realizarlo no sólo un adulto, sino también un menor con edad. En España solo conocemos una sentencia donde el agresor es un menor de 17 años de edad ${ }^{20}$. $Y$ en lo que se refiere a las conductas conocidas como sexting comportan un cuerpo legal relevante en el que se subsumen muchas conductas habituales perpetradas por menores como se ha visto ${ }^{21}$. Pueden revestir formas muy variadas y como señala la Memoria de la Fiscalía General del Estado (2016) su calificación jurídica puede ser dificultosa pues, según los casos, podría encajar al tiempo dentro del delito del artículo 197.7 CP, o en otra modalidad de descubrimiento y revelación de secretos del mismo artículo 197 CP, o en un delito contra la integridad moral del artículo $173.1 \mathrm{CP}$, o en el nuevo delito de acoso del artículo 172 ter. 1.2. ${ }^{\text {. }}$.

Puede colegirse que, los agresores de entre 14 y 18 años autores de conductas de acoso escolar, en su versión tradicional o de ciberbullying o acoso con elementos sexuales (grooming y sexting) responden penalmente; con la particularidad en el caso de sexting, no solo será responsable el menor o menores que lo practiquen; también el menor que recibe las fotos o videos de contenido sexual y los reenvía a otros compañeros del mismo círculo educativo. Así lo hemos constatado en numerosos pronunciamientos judiciales en sede de jurisdicción de menores. No obstante, la Ley Orgánica de Responsabilidad Penal del Menor (LORPM, 2000) dulcifica o atempera los términos de dicha responsabilidad, al configurarla como una responsabilidad distinta de la responsabilidad penal de los adultos, por lo que siendo una responsabilidad formalmente penal, permite una intervención sancionadora-educativa, -aunque desde luego- de especial intensidad.

19 El legislador español se aleja de los modelos previstos en el resto de la normativa europea que le sirve de referente. Tanto en el Convenio de Lanzarote, como en la Directiva 2011/92/UE se exige la incriminación únicamente de los supuestos en que sea un adulto quien realice la proposición al menor.

20 Se le condena por Sentencia del Juzgado de Menores de Orense de 13 de mayo de 2013, confirmada por la Sentencia de la Audiencia Provincial de Ourense de 3 de octubre de 2013.

21 Un amplio estudio sobre la nueva regulación de estas modalidades delictivas puede verse en PÉREZ VALLEJO, A.M ${ }^{a}$. y PÉREZ FERRER, F. Bullying, ciberbulying y acoso con elementos sexuales: desde la prevención a la reparación del daño. Madrid: Editorial Dykinson, 2016. 
Sin obviar que estos menores infractores también responden civilmente por el daño injustamente causado (responsabilidad civil "ex delicto"); en este caso, junto a otros responsables civiles que solidariamente responderán con él: padres, tutores y guardadores (artículo 61.3 y 4 LORPM). No admite matices, que tales comportamientos de hostigamiento derivados de las conductas debullying, ciberbullying, o de las también analizadas conductas conocidas como chid grooming y sexting generan un daño moral resarcible, que corresponde compensar, no sólo por el sufrimiento personal de las víctimas, sino especialmente, por el sentimiento de la dignidad lastimada o vejada, el daño psicológico, la perturbación en el normal desarrollo de la personalidad, y un largo etcétera de padecimientos que ningún ser humano tiene obligación de soportar, menos aún, cuando se producen en la infancia y adolescencia.

\section{Hoja de ruta y principales retos para la intervención. A modo de conclusión}

Ante el panorama anteriormente descrito, a nadie se le escapa que las perspectivas de futuro discurren o deben centrarse en la prevención. Solo a través de políticas públicas de prevención y protección de derechos de niños, niñas y adolescentes se podrá reducir la incidencia de la violencia entre iguales en todas sus manifestaciones en el entorno escolar.

\subsection{Primer estadio de intervención: la Prevención primaria}

La educación y el entorno educativo son claves para combatir este tipo de violencia (Save the Children, 2016, p. 8 y 9). A nuestro modo de ver, las políticas y estrategias de prevención deben partir de un replanteamiento general a propósito de los valores que han de inculcarse a menores y adolescentes en la familia, la escuela y los medios de comunicación.

En la sociedad del siglo XXI hay que someter a consideración y repensar la crisis de valores y adecuadas pautas educativas que 
hoy transmiten las familias a los hijos. Se afirma que, "con frecuencia numerosos comportamientos delictivos responden más bien a modelos educativos no adecuados, definidos, por la laxitud en cuanto a la imposición de límites a los adolescentes" ${ }^{22}$. Los Colegios por su parte son garantes de mejorar la convivencia en sus Centros, prevenir la conflictividad y evitar la aparición de conductas violentas entre iguales, que pudieran desembocar en situaciones de acoso escolar. Por lo que, la educación en valores ${ }^{23}$ la información, la sensibilización y consiguiente toma de conciencia del problema del acoso e intimidación entre iguales, y sus nuevas formas de manifestarse, son las bases de futuro para garantizar la prevención de estas conductas.

Visto el uso irresponsable de las TICS por parte de menores, debe insistirse pues en la educación digital a menores, como una tarea que debe involucrar a padres y centros educativos. De forma paralela, hay que hacer balance y reflexionar sobre el control parental en torno al uso de las nuevas tecnologías; y repensar, adoptando medidas, sobre la edad apropiada para que niñas y niños tengan su primer teléfono móvil, una vez analizados los riegos y peligros que comporta su uso. En este contexto, se plantea una duda a propósito de hasta dónde puede llegar el control parental sobre los dispositivos móviles de los hijos. Esto es, ¿qué debe primar el derecho a la intimidad y al secreto de las comunicaciones de los que son titulares los menores de edad?; o más bien, ¿el derecho-deber de los padres de apartarles de un riesgo cierto que atente con contra su integridad física y mental? La respuesta no ofrece dudas, como confirma la STS de 10 de diciembre de 2015, que viene a avalar el acceso de los padres a las cuentas de Facebook de sus

22 Vid. Memoria de la Fiscalía General del Estado (2013). Ob. cit., p. 409.

23 El Objetivo 6 del II Plan Estratégico Nacional de Infancia y Adolescencia 2013- 2016 (PENIA II) apuesta por garantizar una educación de calidad para todos caracterizada por la formación en valores. En el apartado 6.8 bajo la rúbrica "Educación en valores y prevención del conflicto", el subapartado (6.8.5) viene referirse a la necesidad de promover todas aquellas medidas que prevengan e intervengan en los casos de acoso escolar, corresponsabilizando a los alumnos en el objetivo de un buen clima escolar (p. 51 y 52). 
hijos para evitar el ciberacoso ${ }^{24}$. Dice con acierto el TS que "No puede el ordenamiento hacer descansar en los padres unas obligaciones de velar por sus hijos menores y al mismo tiempo desposeerles de toda capacidad de controlar (...) La inhibición de la madre ante hechos de esa naturaleza, contrariaría los deberes que le asigna por la legislación civil $^{25}$.

Hecho este inciso, y siguiendo nuestro hilo argumental en fase de prevención primaria, cabe someter a revisión las carencias y necesidades detectadas en los Centros educativos a propósito de la actuación (formativa e informativa) sobre el acoso y ciberacoso. Los riesgos e implicaciones jurídicas que llevan aparejada estas prácticas de acoso presenciales y/o en línea, no son del todo conocidos por los menores, sus padres y profesores. Por lo que urge desarrollar e implementar en los Planes de Convivencia de los Centros programas de formación e información homogéneos para padres, docentes y alumnos. A nuestro modo de ver existe una brecha importante entre la información que debe suministrarse a los menores y lo que les informa sobre este particular. Una línea de actuación en este sentido puede ayudar a concienciar y persuadir a los menores (potenciales agresores) sobre la graves consecuencias de la adopción de estas conductas.

De otro lado, también se sitúa el foco de prevención en los medios de comunicación ${ }^{26}$; especialmente la Televisión e internet, deben establecer controles a modo de autorregulación para fijar limitaciones en cuanto a

24 Vid. STS (Sala de lo Penal)10 de diciembre de 2015 Ponente: Antonio del Moral Garcia Roj: STS $5809 / 2015$. En el caso de autos, se cuestiona sobre si son válidas las pruebas obtenidas a través del del acceso a la cuenta abierta por una menor (15 años) en la red social Facebook por parte de su madre sin contar con su consentimiento, ante la sospecha de que pudiera estar siendo víctima de un delito de Child Grooming.

25 Se trataba además de actividad delictiva no agotada, sino viva: es objetivo prioritario hacerla cesar. Tienen componentes muy distintos las valoraciones y ponderación a efectuar cuando se trata de investigar una actividad delictiva ya sucedida, que cuando se trata además de impedir que se perpetúe, más en una materia tan sensible como esta en que las víctimas son menores. $\left.\mathrm{FJ}^{\circ} \mathrm{c}\right)$.

26 Sobre el particular, véase el Objetivo 3 del PENIA II (2013-2016) bajo la rúbrica "Impulsar los derechos y la protección de la infancia con relación a los medios de comunicación y a las tecnologías de la información en general", p. 19. 
determinados contenidos (programas de acción y violencia). Incluso a la hora de difundir informaciones o noticias sobre casos ya verificados de acoso. No obstante, los medios de comunicación se nos presentan como un medio muy útil para la sensibilización y concienciación social frente a este fenómeno.

Por último reseñar que en España se trabaja en la elaboración de un Plan Estratégico de Convivencia Escolar ${ }^{27}$, Según se ha anunciado, el plan tiene su origen en la convicción de que "la convivencia es uno de esos ejes en los que puede haber consenso para el necesario Pacto Nacional de Educación en España"; perspectiva desde la que se abordó su diseño con el objetivo de promover la cooperación entre instituciones y administraciones e "involucrar y hacer partícipes a alumnos y familias".

\subsection{Segundo estadio de intervención: La Prevención secundaria}

Como se ha visto, con frecuencia, en los casos de acoso escolar y ciberacoso, pasan muchos meses, incluso varios años, hasta que la situación de indefensión que genera, produce en la víctima una severa interferencia en su rendimiento escolar, en su comportamiento y autoestima. Síntomas o indicadores que como describen la mayoría de las sentencias consultadas, son tardíamente identificados por los propios padres o por el Colegio ${ }^{28}$, agravando drásticamente la situación. Precisamente, la sutileza de las conductas violentas relacionales en el aula y la ley del silencio que impera, podrían impedir que los adultos sean

27 El Borrador del Plan contempla, entre otras medidas, la puesta en marcha de un teléfono de atención a víctimas de acoso escolar, ya implantado desde el 1 de noviembre de 2016 que funciona las 24 horas del día durante todo el año, de forma gratuita y anónima, ya que las llamadas no quedarán reflejadas en la factura de los usuarios. Asimismo se prevé la elaboración de un protocolo de convivencia escolar, una guía para padres y un manual de apoyo a víctimas de violencia escolar, la creación de un portal Web con buenas prácticas de las comunidades autónomas e información y formación dirigido a los alumnos, familiares y los profesores, la implementación de itinerarios de formación del profesorado en convivencia o la elaboración del Plan Director de Convivencia y Mejora de la Seguridad de los Centros Educativos y sus Entornos Véase el Informe sobre el Plan estratégico de Convivencia Escolar. Enlace: <http://www.lamoncloa.gob.es/consejodeministros/ referencias/Paginas/2016/refc20160122.aspx\#ConvicenciaEscolar>.

28 (...) "la ignorancia institucional puede llevar al encumbramiento de la ley del más fuerte". Así lo señala la Sentencia de la Audiencia Provincial de Madrid de 16 de septiembre de 2014. 
conscientes de la situación que sufren estos estudiantes (POVEDANO et al, 2015). Pero en muchas ocasiones los propios docentes minimizan el problema aduciendo que son "cosas de niños"; y también, como no, en pro de no dañar al imagen del Colegio. Se afirma con rotundidad que frente a la situación de acoso escolar la respuesta es la "negación rotunda" y de "absoluta pasividad" 29 . Por este motivo, se insiste desde los propios Tribunales que "cualquier indicio o signo que el niño/adolescente exprese, de afectación o malestar, en esta dirección, hay que considerarlo sin dilación; procurando, atención ante lo que ocurre, indagando en la realidad que se infiere del problema y aportando soluciones que, primero, respalden y amparen el desvalimiento e indefensión que esté viviendo el niño o adolescente y segundo, incluyan a todos los implicados, para que puedan adoptarse medidas adecuadas que modifiquen el patrón de conducta afectado en la interacción de acoso"30.

Este segundo estadio en sede de prevención, pasa por la adopción de distintas medidas desde el propio ámbito educativo, que, en muchos casos, sin lugar a dudas, resultarán suficientes para poner freno al problema. En España muchas Comunidades Autónomas, en virtud de las competencias que tienen transferidas en materia educativa y que les confiere la Ley Orgánica 2/2006, han creado Protocolos para la identificación y tratamiento del bullying y ciberbullying. Pero desgraciadamente la realidad demuestra que a veces la única solución eficaz para terminar con la situación de acoso, es el cambio de colegio del menor acosado, lo cual, en sí mismo, es un "hecho traumático"31.

Además de estas medidas en sede de prevención, la inclusión de programas de formación en Resolución de Conflictos (ERC) y de Mediación, se nos muestran como una herramienta muy útil. Sabemos que la mediación posee un enorme componente y potencial preventivo,

Vid. Sentencia del TSJ de Madrid, (Sala de lo Contencioso-Administrativo) Sentencia núm. 100/2016 de 24 febrero (JUR 2016195342). Ponente: Rafael Villafañez Gallego.

31 Vid. Sentencia de la Audiencia Provincial de Palencia de 18 de marzo de 2016 (Sección 1ª). Sentencia núm. 55/2016. AC 2016/425. Ponente: Juan Miguel Carreras Maraña. 
educativo o pedagógico (VIANA ORTA, 2012, p. 378 y 394; GORBEÑA ETXEVARRÍA, 2013, p. 107; LÓPEZ PELÁEZ, 2013, p. 191), y aunque en España casi todas las Comunidades Autónomas incluyen esta nueva metodología en sus Planes de convivencia, su efectiva implementación hasta la fecha es residual. En el marco escolar, se nos presenta como altamente positivo implantar programas de mediación entre compañeros/ as en el que los alumnos actúan como mediadores. El proyecto "BeatBullying-mentors", ya en funcionamiento en siete países europeos, forma a jóvenes como mediadores de los conflictos que se dan en las aulas con resultados positivos ${ }^{32}$. No obstante, debemos advertir que cuando la situación de acoso ya está cronificada, no es posible llevar a cabo una mediación, pues supondría situar al mismo nivel de derechos y obligaciones a dos personas que, a priori, ya no están en las mismas condiciones de igualdad.

\subsection{Tercer estadio: Prevención e intervención terciaria}

Este estadio integra medidas de ayuda a los protagonistas directos de los casos de bullying y ciberbullying (víctimas, acosadores y testigos). Urge diseñar un modelo de prácticas o reuniones restaurativas en sede de prevención terciaria, con el fin de minimizar el impacto en situaciones de acoso ya consolidadas. Utilizar medidas terapéuticas, de soporte y protección a las víctimas que eviten una segunda victimización; y de soporte y control a los agresores. Pero también a los familiares, incluidos mecanismos de denuncia ante la Fiscalía de Menores en los casos muy graves.

Cuando las medidas anteriormente referidas en fase de prevención no han funcionado y no es posible la "desjudicialización" del conflicto, víctima y agresor se incorporan al proceso. Llegados a este punto y si los hechos son constitutivos de los delitos que comportan las conductas analizadas, el sistema de justicia penal juvenil debe responder a los

32 Esta iniciativa forma parte de la campaña anti-bullying promovida por la Confederación Española de Centros de Enseñanza (CECE) y la Fundación británica BeatBullying en colaboración con Cooperación internacional ONG. 
objetivos de educación y reinsercción social previstos en la LORPM. En este contexto, la mediación con menores infractores (14 a 18 años) resulta altamente positiva. Implica que el menor infractor se enfrente de manera directa con los efectos de sus actos criminales y se haga responsable de los mismos frente a la víctima.

En efecto, en la propia LORPM se articula la posibilidad de una mediación con menores infractores sobre el reconocimiento expreso del principio de oportunidad en el ejercicio de la acción penal, en concreto, sobre la base de la posibilidad de un sobreseimiento del expediente penal por conciliación o reparación entre el menor y la víctima. La reparación podrá llevarse a cabo en la forma que las partes hayan acordado en el "plan de reparación" que el Juez podrá incluir como contenido de la responsabilidad civil derivada del delito. En consecuencia, la mediación penal con menores infractores no debe entenderse como manifestación del principio de intervención mínima del Derecho Penal, sino más bien, como reflejo del principio de oportunidad (GONZÁLEZ PILLADO, 2012, p. 53-87), del superior interés del menor, así como del principio de proporcionalidad.

Se afirma que la mediación es un modelo idóneo para el sistema de justicia del joven por su escaso valor "estigmatizante", su alto valor pedagógico y su carácter de menor represión (CASTILLEJO MANZANARES, 2011, p. 12). Ventajas no sólo para infractor y víctima, sino también para la propia familia, la comunidad y hasta para el propio Estado. En este sentido, se hace necesaria más que nunca la consecución de una Justicia Restaurativa que permita ante todo la protección de la víctima mediante la reparación de los daños derivados de la acción delictiva; y también al menor infractor, para lograr su reeducación y resocialización.

\section{Conclusiones}

La complejidad del bullying, ciberbullying y otros tipos de acoso con tintes sexuales a través de la red, exige que la actuación ante este tipo 
de maltrato presente en la infancia y adolescencia, adopte un carácter esencialmente preventivo-educativo. La identificación de soluciones y las perspectivas de futuro para abordar la violencia en el entorno escolar (presencial o en línea) pasan por la prevención a distintos niveles y requieren de una acción coordinada de todos los que intervienen en el proceso de socialización del menor. Medidas auspiciadas por profesores implicados, la comunidad escolar y la insustituible colaboración de las familias, por ser ellas quienes pueden, principalmente, identificar los primeros síntomas.

La penosidad e incluso la crueldad que deriva de las conductas de acoso o ciberacoso, destruyen -de inicio- la autoestima de quien lo sufre y le producen secuelas de especial intensidad que pueden marcar toda su vida. Síntomas o indicadores que generalmente son tardíamente identificados por los propios padres, o por el colegio, agravando drásticamente la situación.

Especial atención hay que prestar al creciente aumento del uso de las redes sociales (Tuenti, Facebook o Twitter) como plataformas para la comisión de violencia escolar entre menores que se conocen dentro del mismo círculo educativo. $Y$ es que el uso de los dispositivos móviles se produce a edades cada vez más tempranas y a través de sus aplicaciones (WhatsApp) se emplea en conductas vejatorias, amenazas o para difundir fotos y videos de contenido sensible, sin supervisión y control parental. Con la particularidad de que, en ocasiones, cuando las imágenes son difundidas, puede originarse un proceso de ciberbullying en el que estarán implicados varios menores de edad. Compañeros del menor víctima pueden utilizarlas para mofarse, hacer comentarios dañinos sobre su persona, provocando un sinfín de padecimientos y un atentado a su dignidad y otros derechos fundamentales que ningún menor tiene obligación de soportar.

Poner freno a estas prácticas y al uso irresponsable de las TICs requiere estrategias y medidas coordinadas (padres/docentes) dirigidas a la sensibilización, formación y educación digital. A modo de alerta debe inculcarse a niños, niñas y adolescentes el peligro que acarrea 
difundir contenido sensible por estos medios, pues ya existen datos concluyentes que confirman el riesgo potencial de que aumenten los casos de violencia escolar a través de la utilización de las TICs.

A este contexto de cambio y transformación sin precedentes quieren responder las recientes medidas de sensibilización y las iniciativas legislativas que están por venir. Medidas de distinto orden que, en sede de prevención, como se ha visto en las líneas precedentes, podrían evitar y en su caso, minimizar el impacto de esta lacra social.

\section{Referencias}

BULLYING STATISTICS IN THE UK. THE ANNUAL BULLYING SURVEY (2016). Disponible en: <http://www.ditchthelabel.org/annualbullying-survey-2016/>.

DEL REY, R./ FELIPE, P. y ORTEGA-RUÍZ, Rosario en Bullying and cyberbullying: Overlapping and predictive value of the co-occurrence. Psicothema. v. 24, n. 4, 2012, p. 608-613.

CASTILLEJO MANZANARES, Raquel. La mediación en el proceso de menores. Revista de Derecho Penal, n. 32, 2011. p. 9-28.

FUNDACIÓN ANAR y Fundación Mutua Madrileña. Informe anual 2016. Acoso escolar: I Estudio sobre el bullying según los afectados y líneas de actuación. Madrid, 26 de abril de 2016.

GAIRÍN SALLÁN, J. et al..: El «bullying» escolar. Consideraciones organizativas y estrategias para la intervención. Educación XX1. v. 16, n. 1, 2013. p. 17-38.

GARCÍA GARCÍA, J. et al ORTEGA, E., DE LA FUENTE, L., ZALDÍVAR, F., GIL-FENOY, M.J. (2017) Systematic Review of the Prevalence of School Violence in Spain. Procedia-Social and Behavioral Sciences, 237, p. 125-129.

GONZÁLEZ PILLADO, Esther. La mediación como manifestación del principio de oportunidad en la Ley de Responsabilidad Penal de Menores. En: González Pillado, E. (Coord). Mediación con 
menores infractores en España y los países de su entorno, Tirant monografías, Valencia, 2012. p. 53-87.

GORBEÑA ETXEVARRÍA, L. La mediación en educación infantil y primaria. En: Sánchez-García Arista, Ma Luz (Coord.). Gestión positiva de conflictos y mediación en contextos educativos, Madrid: Reus, 2013.

LÓPEZ PELÁEZ, P.: La educación en valores: Mediación y menores de edad, En: GORJÓN GÓMEZ, F./LÓPEZ PELÁEZ, A. (Coord.) Estado del arte de la mediación. Aranzadi, 2013.

MARTÍNEZ AMORÓS, S.: La vulnerabilidad del menor en las aulas escolares. Construyendo una escuela segura, en Vulnerabilidad infantil: Un enfoque multidisciplinar. (Dir. RODES LLORET F.). Madrid: Díaz de Santos, 2010.

OÑATE, A. y PIÑUEL, I. Informe Cisneros X sobre Acoso y Violencia Escolar. Instituto de Innovación educativa y desarrollo directivo. Septiembre. 2006. Disponible en: <https://convivencia.files. wordpress.com/2012/05/cisneros-xviolencia_acoso-2006120p.pdf>. Consulta en: 20 abr. 2014.

ORJUELA LÓPEZ, L. et al..: Informe sobre Acoso escolar y ciberacoso: propuestas para la acción. Save the Children. Madrid, Octubre, 2013.

PÉREZ VALLEJO, A.M ${ }^{a}$. El complejo régimen que disciplina la responsabilidad civil por daños derivados del acoso escolar. Anuario de Derecho Civil. Tomo LXVIII fasc. IV (2015), p. 1387-1452.

PÉREZ VALLEJO, A.M ${ }^{a}$. y PÉREZ FERRER, F. Bullying, ciberbulying y acoso con elementos sexuales: desde la prevención a la reparación del daño. Madrid: Editorial Dykinson, 2016.

POVEDANO, A., CAVA, M. J., MONREAL, M. C., VARELA, R. Y MUSITU, G. (2015) Victimization, loneliness, overt and relational violence at the school from a gender perspective. International Journal of Clinical and Health Psychology, 15 (1), 44-51.

ROJAS MARCOS, L.: "Los estragos del acoso escolar". EI País. 2 de abril de 2005. Disponible en: <http://elpais.com/diario/2005/04/02/ opinion/1112392807_850215.html>. Consulta en: 20 abr. 2014. 
Save the Children. Yo a eso no juego. Bullying y Ciberbullying en la infancia. (Coord. Ana Sastre). España, 2016.

VIANA ORTA, $\mathrm{M}^{\mathrm{a}} \mathrm{I}$.: Características de la mediación escolar en

España. Estudio comparado entre Comunidades Autónomas. Revista Cuestiones Pedagógicas, n. 22, 2012/213.

Autora Convidada 